\title{
Pengembangan Buku Ajar Mata Kuliah Cross Cultural Understanding (CCU) Berbasis Media Sosial di Program Studi Pendidikan Bahasa Inggris Universitas Nahdlatul Ulama Blitar
}

\author{
Ahmad Saifudin \\ Universitas Nahdlatul Ulama Blitar \\ Email: saif.ahmad123coretandinding@gmail.com
}

\section{Tersedia Online di \\ http://www.jurnal.unublitar.ac.id/ index.php/briliant}

\begin{tabular}{l}
\hline Sejarah Artikel \\
\hline Diterima pada 15 November 2018 \\
Disetuji pada 20 November 2018 \\
Dipublikasikan pada 20 \\
November 2018 Hal. $503-513$ \\
\hline
\end{tabular}

\section{Kata Kunci:}

Pengembangan, $C C U$, Media

Sosial

\section{DOI:}

http://dx.doi.org/10.28926/brilian t.v3i3.252

motivasi dan hasil belajar mahasiswa bahasa Inggris Universitas Nahdlatul Ulama Semester IV.

\section{PENDAHULUAN}

Cross cultural understanding merupakan salah satu mata kuliah keahlian berkarya (MKB) yang wajib diampu oleh mahasiswa program studi bahasa inggris di Universitas Nahdlatul Ulama Blitar. Mata kuliah ini wajib ditempuh oleh mahasiswa bahasa inggris semester IV.

Linton (in Mesthrie, et al., 2009: 28) defines culture as the way of life of its members; the collection of ideas and habits which they learn, share and transmit from generation to generation. This means that culture also functions as design for living, which gives meaning to the way and the form of habits considered appropriate and acceptable within a certain community group, while language is treated as a cultural activity and, at the same time, an instrument for organizing other cultural domains (Sharifian \& Palmer, 2007: 1).

Menurut Linton budaya adalah sebagai cara hidup bagi manusia. Hal ini bermaksud bahwa budaya dapat berfungsi sebagai desain dari kehidupan yang memberi makna pada cara dan bentuk kebiasaan yang dianggap tepat dan dapat diterima dalam kelompok komunitas tertentu. Sementara bahasa diperlakukan sebagai kegiatan budaya dan pada saat yang sama, instrumen untuk mengatur domain budaya lainnya. 
Dalam konteks ini, Taylor (dalam Peoples \& Bailey, 2009: 22) mendefinisikan budaya sebagai keseluruhan yang utuh yang mencakup pengetahuan, keyakinan, seni, moral, hukum, adat istiadat, dan kemampuan serta kebiasaan lain yang diperoleh oleh manusia sebagai anggota masyarakat. Dengan kata lain, pengetahuan, keyakinan, seni, moral, hukum, tradisi dan praktik lain yang diperoleh oleh manusia sebagai bagian dari masyarakat, merupakan komponen budaya. Peoples dan Bailey (2009) menyimpulkan bahwa budaya dipelajari, dibagikan, dan dimiliki bersama.

Menurut Koentjaraningrat sebagaimana dikutip Abdul Chaer dan Leonie Agustina dalam buku Sosiolinguistik bahwa bahasa bagian dari kebudayaan. Jadi, hubungan antara bahasa dan kebudayaan merupakan hubungan yang subordinatif, di mana bahasa berada di bawah lingkup kebudayaan. Namun pendapat lain ada yang mengatakan bahwa bahasa dan kebudayaan mempunyai hubungan yang koordinatif, yakni hubungan yang sederajat, yang kedudukannya sama tinggi.

Bahasa adalah sebuah sistem, artinya, bahasa itu dibentuk oleh sejumlah komponen yang berpola secara tetap dan dapat dikaidahkan. Sebagai sebuah sistem, bahasa bersifat sistematis dan juga bersifat sistemis. Sistematis artinya bahasa itu tersusun menurut suatu pola tertentu. Sistemis artinya bahasa tersebut bukan merupakan sebuah sistem tunggal, melainkan terdiri dari sejumlah subsistem.

Sistem bahasa yang dimaksud di atas adalah berupa lambang-lambang dalam bentuk bunyi yang lazim disebut bunyi ujar atau bunyi bahasa. Setiap lambang bahasa mengandung sesuatu yang disebut makna atau konsep. Bahasa sebagai sebuah lambang bunyi yang bersifat manasuka (arbitrer), konvensional, produktif serta dinamis mempunyai banyak fungsi. Menurut Dell Hymes (1964) ada lima fungsi bahasa, yaitu;

(1) menyesuaikan diri dengan norma-norma sosial,

(2) menyampaikan pengalaman tentang keindahan, kebaikan, keluhuran budi,

(3) mengatur kontak sosial,

(4) mengatur perilaku, dan

(5) mengungkapkan perasaan

Keanekaragaman bahasa memang tidak dapat dilepaskan dari keanekaragaman budaya. Bahasa merupakan aspek dari budaya. Hal ini dibuktikan dengan banyaknya fakta yang menunjukkan hubungan yang erat antar keduanya. Bahasa suatu kaum atau bangsa, baik dari segi pengucapan dan gerak tubuh saat bertutur dapat menunjukkan seberapa kuat budaya bangsa tersebut. Bisa dikatakan bahwa bahasa adalah produk dari suatu budaya.

Dalam hal ini mata kuliah Cross Cultural Understanding sangat penting untuk dipelajari demi memahami budaya dari berbagai negara, daerah dan kelompok etnik. Pemahaman lintas budaya yang luas akan membantu para negosiator dan komunikator dalam melakukan dialog antar budaya. Pemahaman lintas budaya sebelum melakukan komunikasi lintas budaya akan meningkatkan peluang keberhasilan dari tujuan komunikasi tersebut.

Karena dengan menguasai Cross Cultural Understanding berarti kita dapat mengetahui suatu budaya dari sebuah Negara yang akan kita tuju. Sehingga hal ini akan meminimalisir kesalahpahaman dalam berbicara atau berinteraksi. 
Pemahaman lintas budaya yang baik akan meningkatkan kemungkinan keberhasilan dalam negosiasi. Sesuatu hal sangat mudah untuk dipahami jika salah satu komunikator telah bertemu dengan partner komunikasinya sebelum komunikasi dimulai dan diasumsikan memiliki percakapan yang menyenangkan serta mengerti budaya masing-masing individu pada saat berkomunikasi. Dengan pola komunikasi seperti ini, akan memudahkan pencapaian dari tujuan komunikasi.

Pendidik diharapkan dapat mengembangkan materi pembelajaran sesuai PP Nomor 19 Tahun 2005 Pasal 20. Hal ini dipertegas malalui Permendiknas Nomor 41 Tahun 2007 tentang Standar Proses yang berbunyi perencanaan proses pembelajaran yang mensyaratkan pendidik untuk mengembangkan rencana program semester (RPS). Salah satu komponen RPS adalah materi ajar. Dengan demikian, pendidik harus mengembangkan materi ajar atau bahan ajar sebagai salah satu sumber belajar.

Bahan ajar adalah bahan-bahan atau materi pelajaran yang disusun secara sistematis, yang digunakan pengajar dan peserta didik dalam proses pembelajaran (Andi, 2011:16). Lebih lanjut, Ahmad (2012: 102) menjelaskan bahwa bahan ajar adalah materi yang akan diajarkan kepada peserta didik yang telah dipilih (diseleksi), atau bahan ajar adalah materi (pesan) yang harus dipelajari dan dipahami oleh peserta didik. Maka dapat disimpulkan bahan ajar adalah bahanbahan atau materi pelajaran yang disusun secara sistematis, yang digunakan guru dan peserta didik dalam proses pembelajaran.

Mulyasa (2006: 154) menjelaskan prinsip-prinsip pengembangan bahan ajar adalah kesesuaian (Validity), berkaitan dengan tingkat kesesuaian dan keterujian materi dengan kompetensi, tingkat kepentingan (significance), kegunaan (utility), kemungkinannya untuk dipelajari (learnability), berkaitan dengan kemungkinan materi tersebut untuk dipelajari, baik berkaitan dengan ketersediaan maupun kelayakan materi untuk dipelajari dan kemudahan untuk memperolehnya, kemenarikan (interest), berkaitan dengan kemenarikan tingkat materi, sehingga dapat mendorong dan membangkitkan anfsu belajar peserta didik untuk mengadakan berbagai pengakajian lebih lanjut. Dalam hal ini untuk mendukung pengembangan bahan ajar yang sesuai, teruji, berguna, mudah dipelajari dan menarik bagi pengguna, peneliti akan menyusun bahan ajar Cross Cultural Understanding berbasis media sosial.

Media sosial atau social media setiap waktu menjadi fenomena global dan mengakar. Keberadaan media sosial tidak dapat dipisahkan dari teknik berkomunikasi setiap individu. Mayfield (2008:74) menyatakan bahwa sosial media adalah media di mana penggunanya dengan mudah berpartisipasi di dalamnya, berbagi dan menciptakan pesan, termasuk blog, jejaring sosial, wiki/ensiklopedia online, forum-forum maya, termasuk virtual worlds (dengan avatar/karakter 3D). Defenisi ini dirasa lebih mudah untuk dipahami.

Dengan adanya media sosial ini tentu dapat membantu kita dalam bersosialisasi dan bernegoisasi dengan tanpa ada sekat lagi. Hal ini tentu memudahkan urusan dan pekerjaan manusia di bumi. Henderi dan Yuliana Isma (2007: 2) menjelaskan bahwa media sosial adalah situs jaringan sosial seperti layanan berbasis web yang memungkinkan individu untuk membangun profil publik atau semi-publik dalam sistem terbatasi, daftar pengguna lain dengan siapa 
mereka terhubung, dan melihat dan menjelajahi daftar koneksi mereka yang dibuat oleh orang lain dengan suatu sistem.

Kotler dan Keller (2012: 568-570) ada tiga platform utama untuk media sosial yaitu Online Communities and Forums, Blogs, dan Social Networks. Grant dan Lei (2001: 10-11) claim that -Cultural differences are the main issues in cross-cultural education." Without recognizing differences in traditions and habits among people of different ethnics, religions, localities, regions, and countries or nations, confusion and misunderstanding will continually recur in communication with other communities. Pada CCU dipelajari pemahaman mengenai perbedaan budaya yang berupa suatu pengenalan tentang perbedaan budaya asing dalam kehidupan atau yang mengkaji tentang suatu kebiasaan antar Negara yang bertujuan untuk mendapatkan pemahaman atas perbedaan budaya dan kebiasaan dari kedua Negara tersebut.

Hasil observasi yang telah dilakukan menunjukkan bahwa hasil belajar mahasiswa Program Studi Pendidikan Bahasa Inggris pada mata kuliah ini masih rendah, dengan hasil rata-rata belajar yang hanya mencapai 60 menunjukkan jika mahasiswa mengalami kesulitan dalam memahami bahan ajar. Hal ini disebabkan oleh kurangnya fasilitas dan tempat praktik mata kuliah Cross Cultural Understanding dan kurangnya alat untuk menyampaikan materi untuk mencapai tujuan pembelajaran tersebut. Dosen juga mendapat kesulitan dalam menemukan buku yang sesuai dengan kurikulum Prodi S1 Pendidikan Bahasa Inggris untuk mata kuliah Cross Cultural Understanding. Maka dari itu, dosen hanya membuat power point slide sebahai handout materi pembelajaran. Selama ini, belum ada buku ajar yang telah dihasilkan oleh dosen mata kuliah Cross Cultural Undersanding di Prodi S1 Pendidikan Bahasa Inggris Universitas Nahdlatul Ulama.

Melihat fakta diatas tim pengusul mencoba bersinergi untuk menciptakan bahan ajar Cross Cultural Understanding berbasis media yang tepat bagi mahasiswa pada khususnya dan pengembangan ilmu pada umumnya. Dan diharapkan buku atau modul yang dibuat dapat menyajikan materi yang sesuai dengan garis besar pembelajaran yang termuat didalam kurikulum dan tentunya selain mudah dan menarik untuk dipelajari juga memperoleh output yang maksimal.

\section{METODE}

Jenis Penelitian yang pengusul akan lakukan adalah desain (Design Research). Penelitian ini dilaksanakan dengan tujuan untuk mengembangkan dan menghasilkan sebuah produk sebagai suatu pemecahan masalah yang ada di dunia pendidikan. Produk yang akan dihasilkan dalam peneltian ini yaitu buku ajar mata kuliah Cross Cultural Understanding dimana sebelumnya belum ada bahan ajar atau hand book. Mata kuliah Cross Cultural Understanding di lingkungan Universitas Nahdlatul Ulama pada prodi bahasa Inggris diajarkan pada mahasiswa semester IV Prodi S1 Pendidikan Bahasa Inggris Universitas Nahdlatul Ulama tahun akademik 2018/2019.

Model Penelitian ini menggunakan model pengembangan dimana langkahlangkah yang dilakukan secara sistematis dalam proses perancangan dan pengembangan buku ajar yang diwujudkan dalam bentuk diagram atau narasi. 
Penelitian ini menggunakan model pengembangan yang diadaptasi dari model yang dikembangkan oleh Plomp yang disebut sebagai model penelitian Plomp.

Berdasarkan Plomp and Nieveen (2013: 30), ada tiga tahapan dalam penelitian pengembangan Model Plomp ini, yaitu:

1. Fase analisis pendahuluan (Preliminary Research),

2. Fase pengembangan atau pembuatan prototype (Development or Prototyping Phase),

3. Fase penilaian (Assessment Phase) yang diilustrasikan pada gambar 3.1 di bawah ini.

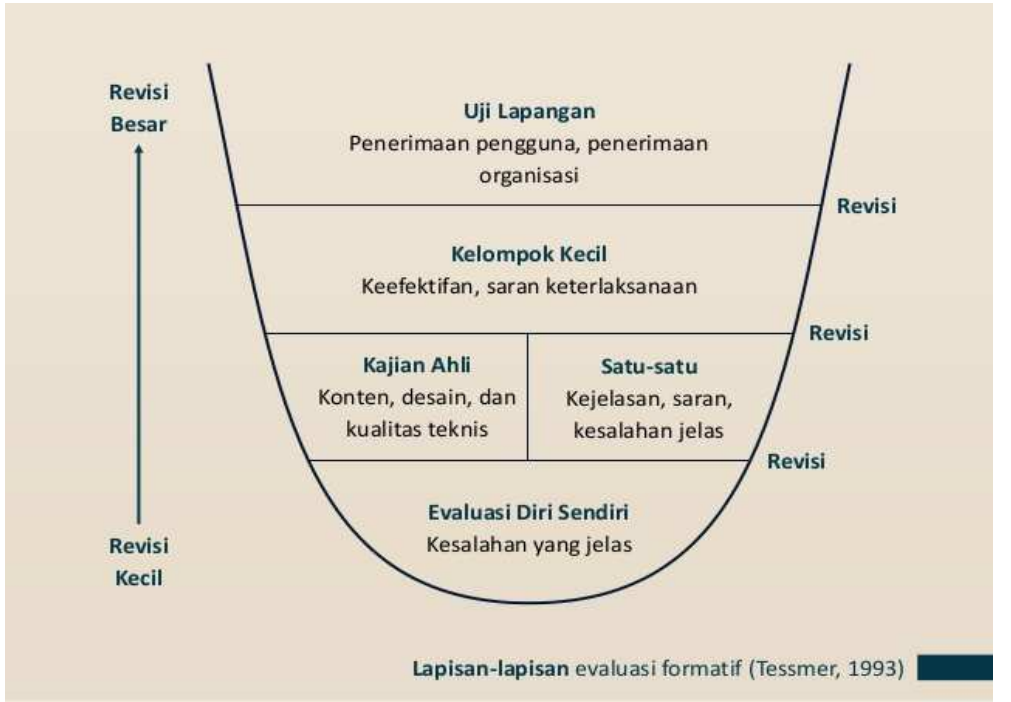

Gambar 3.1. Lapisan-Lapisan Evaluasi Formatif Model Pengembangan Plomp

(Sumber: Tessmer dalam Plomp and Nieveen (2013: 36)

Berdasarkan gambar diatas, kegiatan-kegiatan evaluasi formatif dilaksanakan melalui evaluasi diri (self-evaluation); penilaian ahli (expert review); evaluasi perorangan (one-to-one evaluation); sebagai berikut:

\section{Evaluasi diri (Self-Evaluation)}

Peneliti memeriksa atau mengevaluasi sendiri prototipe 1 yang telah dirancang.

Dalam pemeriksaan ini peneliti telah membuat prototipe yang dirancang yang kemudian dilakukan pemeriksaan apakah prototipe yang dibuat sesuai dengan yang diharapkan atau yang dibutuhkan peserta didik. Setelah dilakukan pemeriksaan kemudian dilakukan evaluasi.

Dari hasil evaluasi itu akan diketahui apakah prototipe yang telah dirancang layak untuk diberikan kepada peserta didik ataukah perlu adanya revisi. Peneliti berusaha untuk melakukannya secara objektif.

\section{Penilaian Ahli (Expert Review)}

Pada tahapan ini, para ahli diminta mengevaluasi atau memberikan penilaian dan saran-saran terhadap rancangan produk untuk menentukan kekurangan dari rancangan produk yang dan kelebihan, serta memperhatikan spesifikasi produk yang diharapkan yaitu berdasarkan aspek didaktik, aspek isi, aspek bahasa, dan aspek penyajian/ kegrafikan. Sehingga dengan adanya penilaian dari ahli 


\section{Evaluasi Perorangan (One-to-one Evaluation)}

Tahapan ini dilaksanakan terhadap dua orang peserta didik yang memiliki kemampuan berbeda-beda (heterogen). Peserta didik diminta untuk memberikan komentar mengenai kepraktisan buku ajar mata kuliah Cross Cultural Understanding yang dikembangkan.

\section{Evaluasi Kelompok Kecil (Small Group Evaluation)}

Tahapan ini dilaksanakan terhadap enam orang peserta didik yang memiliki kemampuan heterogen. Peserta didik belajar dengan menggunakan buku ajar mata kuliah Cross Cultural Understanding pada keadaan yang disetting menyerupai pembelajaran di kelas. Peserta didik diminta untuk memberikan penilaian terhadap buku ajar mata kuliah Cross Cultural Understanding yang sudah dikembangkan.

\section{Uji lapangan (Field Test)}

Pada tahapan ini dilakukan evaluasi yang pelaksanaan pembelajaran pada suatu kelas, dan dilakukan penilaian terhadap buku ajar mata kuliah Cross Cultural Understanding yang sudah selesai dikembangkan tapi masih membutuhkan atau memungkinkan adanya revisi akhir.

Penelitian ini akan dilaksanakan di Prodi S1 Pendidikan Bahasa Inggris Universitas Nahdlatul Ulama. Waktu penelitian dilakukan pada semester genap tahun ajaran 2018/2019.

Penelitian ini dilaksanakan berdasarkan latar belakang permasalahan bahwa mata kuliah Cross Cultural Understanding dianggap sebagai salah satu mata kuliah yang sulit bagi mahasiswa Prodi S1 Pendidikan Bahasa Inggris Universitas Nahdlatul Ulama Blitar. Hasil observasi yang telah dilakukan menunjukkan bahwa hasil belajar mahasiswa Program Studi Pendidikan Bahasa Inggris pada mata kuliah Cross Cultural Understanding masih rendah, dengan hasil rata-rata belajar yang hanya mencapai 60 . Hasil belajar $C C U$ yang rendah disebabkan oleh kurangnya fasilitas dan tempat praktik mata kuliah CCU dan kurangnya alat untuk menyampaikan materi untuk mencapai tujuan pembelajaran tersebut. Proses perkuliahan mata kuliah $C C$ dapat berjalan dengan baik dan dapat mencapai tujuan kompetensi yang diharapkan. Jika ada tindakan atau perubahan yang signifikan diantara dosen dan mahasiswa.

Tujuan dari penelitian ini adalah untuk mengembangkan buku ajar mata kuliah Cross Cultural Understanding berbasis media sosial yang akan digunakan dalam proses perkuliahan dengan bantuan media sosial. Hal ini bertujuan untuk membentuk kebiasaan mahasiswa dalam berkomunikasi dengan menggunakan bahasa inggris.

Materi perkuliahan dibuat berdasarkan literasi yang ada dimedia sosial dan pelaksanaan pembelajaran dilaksanakan dengan menggunakan buku ajar dan media sosial. Perkuliahan dilaksanakan secara online melalui media sosial dan secara offline yang dilaksanakan didalam kelas. Buku ajar sebagai sumber materi yang dapat membantu mahasiswa belajar mandiri, dan media sosial sebagai media dan tempat praktik berbahasa inggris bagi mahasiswa.

Mahasiswa semester empat Prodi S1 Pendidikan Bahasa Inggris Universitas Nahdlatul Ulama tahun pelajaran 2017/2018 merupakan subjek penelitian ini. Penggunaan buku ajar dan media social, perangkat pengajaran, dan analisis kekurangan bahan ajar yang digunakan serta nantinya menjadi bahan 
kajian dalam penelitian pengembangan yang akan menghasilkan sebuah buku ajar ini merupakan data yang akan dikumpulkan dalam penelitian ini.

Sedangkan prosedur penelitian meliputi; Persiapan Penelitian dan pelaksanaan penelitian. Persiapan penelitian meliputi; observasi awal alat bantu pembelajaran yang digunakan, perijinan tempat penelitian dan persiapan instrumen penelitian (RPS dan draft buku ajar). Adapun pelaksanaan penelitian meliputi; potensi dan masalah, Pengumpulan data, desain produk (pembuatan produk), validasi expert, uji coba One-to-one, revisi produk, uji coba Field Test, revisi produk pemakaian, dan produk akhir.

Metode pengumpulan data meliputi target, metode, instrumen dan subjek penelitian. Adapun yang pertama dilakukan adalah meminta tanggapan kepada mahasiswa terhadap buku ajar melalui lembar angket. Yang dilakukan berikutnya adalah meminta tanggapan kepada dosen terhadap buku ajar melalui lembar angket dan wawancara.

Metode pengumpulan data yang ketiga adalah memberikan tes dan tugas berupa soal tes materi kepada mahasiswa untuk mengetahui hasil belajar siswa. Dan yang terakhir adalah mengetahui aktivitas siswa melalui lembar observasi.

Berikutnya Data hasil tanggapan mahasiswa dan dosen berupa angket dianalisis dengan langkah-langkah sebagai berikut:

$$
\text { Skor Tanggapan (\%) }=\frac{\text { Tumlah skor yang didapat }}{\text { Jumlah Skor Maksimal }} \times 100 \%
$$

Persentase yang telah diperoleh kemudian disesuaikan dengan parameter sebagai berikut (menurut Arikunto 2006):

$$
\begin{aligned}
& 85 \%-100 \%=\text { Sangat aktif } \\
& 70 \%-84 \%=\text { Aktif } \\
& 60 \%-69 \%=\text { Cukup aktif } \\
& 50 \%-59 \%=\text { Kurang aktif } \\
& <50 \%=\text { Tidak aktif }
\end{aligned}
$$

Penilaian secara klasikal dihitung dengan menggunakan rumus sebagai berikut (Sudijono 2003).

$$
\begin{aligned}
& P=\frac{f}{N} \times 100 \% \\
& \mathrm{P}=\text { Persentase (ketuntasan hasil belajar secara klasikal) } \\
& \mathrm{f}=\text { frekuensi yang sedang dicari persentasenya } \\
& \mathrm{N}=\text { Jumlah siswa keseluruhan }
\end{aligned}
$$

Sedangkan Hasil belajar mahasiswa di analisis secara deskriptif kuantitatif dengan menghitung nilai rata-rata dari nilai tugas dan nilai tes. Nilai akhir atau nilai hasil belajar siswa secara individu dihitung dengan rumus:

$$
\begin{aligned}
& N A=\frac{\mathrm{a}+2 \mathrm{~B}}{3} \times 100 \\
& \text { Keterangan } \\
& \mathrm{NA}=\text { nilai akhir } \\
& \mathrm{A}=\text { nilai tugas } \\
& \mathrm{B}=\text { nilai tes }
\end{aligned}
$$


Adapun mahasiswa dikatakan tuntas dalam pembelajaran apabila mencapai nilai $\geq 70$, sesuai dengan nilai standar minimum yang ditetapkan oleh Prodi S1 Pendidikan Bahasa Inggris. Perkuliahan dengan menggunakan buku ajar ini dianggap tuntas bila mencapai nilai $\geq 75$.

Persentase ketuntasan mahasiswa secara klasikal dihitung dengan menggunakan rumus menurut Sugiyono (2003) dengan rumus sebagai berikut:

$$
P=\frac{f}{N} \times 100 \%
$$

\section{HASIL}

Berdasarkan observasi yang dilakukan pada mata kuliah Cross Cross Cultural Understanding pada semester IV menunjukan bahwa hasil belajar mahasiswa Program Studi Pendidikan Bahasa Inggris pada mata kuliah ini masih rendah.

Maka dari itu, dosen hanya membuat power point slide sebagai handout materi pembelajaran. Selama ini, belum ada buku ajar yang telah dihasilkan oleh dosen mata kuliah Cross Cultural Undersanding di Prodi S1 Pendidikan Bahasa Inggris Universitas Nahdlatul Ulama. Oleh karena itu peneliti membuat buku baru Cross Cultural Understanding yang mempelajari budaya dari berbagai negara, daerah dan kelompok etnik.

Pemahaman lintas budaya yang luas akan membantu para negosiator dan komunikator dalam melakukan dialog antar budaya. Pemahaman lintas budaya sebelum melakukan komunikasi lintas budaya akan meningkatkan peluang keberhasilan dari tujuan komunikasi tersebut. Pemahaman lintas budaya yang baik akan meningkatkan kemungkinan keberhasilan dalam negosiasi. Sesuatu hal sangat mudah untuk dipahami jika salah satu komunikator telah bertemu dengan partner komunikasinya sebelum komunikasi dimulai dan diasumsikan memiliki percakapan yang menyenangkan serta mengerti budaya masing-masing individu pada saat berkomunikasi. Dengan pola komunikasi seperti ini, akan memudahkan pencapaian dari tujuan komunikasi. Oleh karena itu melalui pola itu peneliti menyajikan materi Cross Cultural Understanding berbasis media sosial di mana penggunanya dengan mudah berpartisipasi di dalamnya, berbagi dan menciptakan pesan, termasuk blog, jejaring sosial, wiki/ensiklopedia online, forum-forum maya, termasuk virtual worlds (dengan avatar/karakter 3D).

Setelah dilakukan evaluasi formatif yang mengacu pada model pengembangan penelitian yang diadaptasi dari model pengembangan Plomp meliputi; evaluasi diri, penilaian ahli, evaluasi perorangan, evaluasi kelompok kecil, dan uji lapangan telah ditemukan bahwa mahasiswa mengalami peningkatan dalam belajar dan memahami mata kuliah Cross Cultural Understanding. Mahasiswa yang pada awalnya rata-rata nilai mata kuliah ini adalah 60 meningkat menjadi 80.

Selain itu mahasiswa lebih aktif dalam memepelajari mata kuliah ini, karena handbook yang dikembangkan dengan berbasis media sosial telah membuat mahasiswa aktif untuk melihat dan mengetahui Cross Cultural Understanding di negara-negara dunia. Hal ini tentunya menambah referensi dan pengetahuan yang lebih kompleks dan general terkait dengan mata kuliah Cross Cultural Understanding.

510 BRILIANT: Jurnal Riset dan Konseptual Volume 3 Nomor 4, November 2018 


\section{PEMBAHASAN}

Penelitian ini menggunakan model pengembangan yang diadaptasi dari model yang dikembangkan oleh Plomp yang disebut sebagai model penelitian Plomp. Berdasarkan Plomp and Nieveen (2013: 30), ada tiga tahapan dalam penelitian pengembangan Model Plomp ini, yaitu fase analisis pendahuluan (Preliminary Research), fase pengembangan atau pembuatan prototype (Development or Prototyping Phase), dan fase penilaian (Assessment Phase).

Pada fase pendahuluan (Preliminary Research) ini peneliti melakukan observasi kepada mahasiswa semester IV mata kuliah Cross Cultural Understanding Program Studi Bahasa Inggris Universitas Nahdlatul Ulama Blitar, dimana saat dilakukan wawancara ditemukan bahwa mahasiswa masih mengalami kesulitan dalam memahami mata kuliah Cross Cultural Understanding yang materinya disampaikan melalui power point. Hal ini dikarenakan dosen kesulitan mendapatkan materi atau buku Cross Cultural Understanding.

Selain wawancara, peneliti juga memberikan angket kepada mahasiswa dan ditemukan bahwa $80 \%$ dari mahasiswa masih mengalami kesulitan dalam memahami materi Cross Cultural Understanding.

Setelah fase pendahuluan (Preliminary Research selesai peneliti mendalami fase pengembangan atau pembuatan prototype (Development or Prototyping Phase). Dalam fase ini peneliti membuat modul Cross Cultural Understanding yang berbasis media sosial di mana penggunanya dengan mudah berpartisipasi di dalamnya, berbagi dan menciptakan pesan, termasuk blog, jejaring sosial, wiki/ensiklopedia online, forum-forum maya, termasuk virtual worlds (dengan avatar/karakter 3D). Sehingga ini dirasa lebih mudah untuk dipahami.

Setelah dilakukan pengembangan atau pembuatan prototype (Development or Prototyping Phase) maka peneliti melakukan fase penilaian (Assessment Phase). Dalam fase ini peneliti memberikan soal tentang materi yang telah diberikan dan $80 \%$ mahasiswa mendapatkan nilai di atas rata-rata. Sedangkan $20 \%$ mahasiswa mendapat nilai cukup. Selain diberikan soal, mahasiswa juga diberikan lembar angket tentang kepuasan terhadap materi Cross Cultural Understanding yang berbasis media sosial, dan $80 \%$ mahasiswa merasa puas terhadap materi yang diberikan dan $20 \%$ merasa cukup.

\section{KESIMPULAN}

Kesimpulan dalam penelitian ini bahwa materi Cross Cultural Understanding berbasis media sosial lebih diminati mahasiswa dari pada materi lama. Hal ini terbukti bahwa tingkat kehadiran mahasiswa meningkat dalam pembelajaran mata kuliah ini.

Selain itu, mahasiswa lebih semangat dalam mendalami materi yang diberikan. Hal ini terbutkti yang pada awalnya nilai rata-rata mata kuliah ini adalah 60 naik menjadi 80 setelah diberikan materi Cross Cultural Understanding berbasis media sosial. Hal ini membuktikan bahwa materi Understanding berbasis media sosial ini bisa diterima mahasiswa.

Dengan materi berbasis media sosial, mahasiswa dengan mudah berpartisipasi di dalamnya, berbagi dan menciptakan pesan, termasuk blog, jejaring sosial, wiki/ensiklopedia online, forum-forum maya, termasuk virtual worlds (dengan avatar/karakter 3D). Dan tugas-tugas kampus bisa dikirim melaui 
online. Sehingga ini dirasa lebih mudah untuk dipahami. Hal ini terbukti tingkat kepuasan mahasiswa terhadap materi ini mengalami peningkatan yaitu $80 \%$ yang awalnya

\section{SARAN}

Kepada dosen program studi bahasa inggris bisa menjadikan materi ini sebagai referensi atau bahan ajar untuk memberikan mata kuliah Cross Cultural Understanding kepada mahasiswa. Materi ini memberikan kemudahan dalam mempelajari budaya sebagai ajakan untuk terus mengembangkan bahan ajar yang mudah, singkat, menyenangkan dan murah.

Selain itu pembelajaran ini bisa memberi motivasi dan semangat baru bagi mahasiswa dalam perkuliahan, membantu dalam pembelajaran mandiri mahasiswa, serta bertambahnya keterampilan mahasiswa dalam menggunakan sumber belajar.

\section{DAFTAR RUJUKAN}

Ahmad, Zainal Arifin. 2012. Perencanaan Pembelajaran. Yogyakarta: Pedagogia. Anas Sudijono. 2003. Pengantar Statistik Pendidikan. Bandung: PT Raja Grapindo Persada.

Andi, Prastowo. 2011. Metode Penelitian Kualitatif. Yogyakarta: A-Ruzz Media. Arikunto,Suharsimi. 2006. Prosedur Penelitian Suatu Pendekatan Praktik. Jakarta: Aneka Cipta.

Bennet, J. M., Bennet, M. J., \& Allen, W. (2003) Developing Intercultural Competence In The Language Classroom. In lange, D. L., \& Paige, M. (Eds.). Culture As The Core: Perspectives On Culture In Second Language Learning (pp. 237- 270). Greenwich: Information Age Publishing.

Brett, J. M. (2000) Culture and Negotiation. International Journal of Psychology Vol. 32 No. 2.

Cameron, L. 2004 Teaching Language to Young Learner. Cambridge: Cambridge University Press.

Corbett, J. (2003). An Intercultural Approach To Second Language Education. In Corbett, J. (Ed.). An Intercultural Approach To English Language Teaching (pp. 1-30). Clevedon, England : Multilingual Matters.

Danesi, Marcel. (2004) Pesan, Tanda, dan Makna: Buku Teks Besar Mengenai Semiotika dan Teori Komunikasi. Yogyakarta : Jalasutra.

Danesi, Marcel (2012) Popular Culture: Introductory Perspectives. Maryland: Rowman and Littlefield Publishers, Inc,

Gumperz, John. J. (1982) Discourse strategies. New York : Cambridge University Press

Koentjaraningrat (1986) Pengantar Ilmu Antropologi. Jakarta : Penerbit Aksara Baru

Koentjaraningrat (2000) Kebudayaan Mentalitas dan Pembangunan (cetakan kesembilan belas). Jakarta : PT. Gramedia Pustaka Utama

Liliweri, Alo. (2004) Dasar-Dasar Komunikasi Antar Budaya. Yogyakarta : Pustaka Pelajar

Leung.K, Rabi S.B., Buchan, N.R, Erez., M \& Gibson, C.B. (2005) Culture and International Business: Recent Advances and Their Implications for Future Research. Journal of International Business Studies, Vol 36, No. 4. 
Mathew, Brita \& Kurnia Ningsih. 2017 Cross-Cultural Understanding a Textbook 2nd edition. Bandung: Angkasa.

Nishimura, S., Anne Nevgi and Seppo Tella. (2009) Communication Style and Cultural Features in High/Low Context Communication Cultures:A Case Study of Finland, Japan and India. Artikel dapat diunduh di: www.helsinki.fi/ tella/nishimuranevgitella299.pdf.

Salacuse, J. W. (2005) Negotiating: The Top Ten Ways That Culture Can Affect Your Negotiation. Ivey Business Journal, Vol. 69, No. 4.

Sugiyono. 2006. Statistika Untuk Penelitian. Bandung: Alfabeta

Sumarno, Marno. (1988) Pragmatik dan perkembangan mutakhirnya dalam Pelba. Lembaga Bahasa Unika Atmajaya : Jakarta

Storey, J. ( 2003) Teori Budaya dan Budaya Pop: Memetakan Lanskap Konseptual Cultural Studies. Yogyakarta : CV. Qalam Yogyakarta 